\title{
Formal Features and Parameter Setting: A View from Portuguese Past Participles and Romance Future Tenses*
}

(Traços formais e fixação de parâmetro: uma perspectiva a partir dos particípios passados do português e do futuro românico.)

\author{
Lucia LoBATO \\ (Universidade de Brasília)
}

ABSTRACT: This paper examines the morphophonological shape of Portuguese past participles, including the stress placement change that took place from Latin to Portuguese in these forms, and argues for a concept of formal feature more abstract than the concept of morphosyntactic feature. Parameter setting is treated as relating to the location in which the configuration of formal features relevant to grammatical semantic interpretation is visible to the PF system. The stages in the development of the Romance future tenses are claimed to follow from a shift in the visibility of the sentential functional heads.

KEY WORDS: Portuguese past participles, Romance future tenses, Stress, Formal feature, Grammaticalization, Parameter setting, Language change.

RESUMO: Este artigo examina a forma morfofonológica dos particípios passados do português, incluindo a mudança na colocação do acento ocorrida na evolução do latim para o português, e argumenta a favor de um conceito de traço formal mais abstrato do que o de traço morfossintático. A fixação paramétrica é tratada como uma questão da localização onde a configuração de traços formais relevante para a interpretação semântica gramatical é visível para o sistema PF. Os estágios no desenvolvimento do futuro românico são analisados como decorrentes de uma mudança na visibilidade dos núcleos funcionais sentenciais.

PalaVRAS-CHAVE: Particípio passado português, Futuro românico, Acento, Traço formal, Gramaticalização, Fixação de parâmetro, Mudança lingüística.

\footnotetext{
* It is a great pleasure to dedicate this paper to Mary Kato, who has been responsible for the training of more than one generation of Brazilian linguists in the investigation of language variation and change, and who gave to Brazilian linguistics a characteristic profile, beyond the barriers among theories. The paper, written in 1998 and revised in June 2000, presents part of the results of a research project on formal features funded by a grant from CNPq. I express my deepest gratitude to Ken Hale for his comments on a preliminary draft of the first version. I would also like to thank Anna Roussou for kindly giving me access to unpublished and as yet undistributed work, Mark Ridd for editorial collaboration, and Orlene Carvalho, Acrisio Pires, Cilene Rodrigues and John Schmitz for logistic and bibliographical help.
} 


\section{Introduction}

The central thesis of this paper is that each generation by the computational system produces a "formal" structure that is analyzed from two different perspectives - phonological and semantic. This structure is formal because it is built with formal features and formal features do not have phonological or semantic "substance". And it is possible to have two different levels of analysis for a single structure because formal features are simultaneously visible to phonological and semantic interpretation. Formal features are also defined as the only features in language actively involved in the building of structures. This means that the abstract features that drive linguistic construction and interpretation are formal features.

The paper argues that this approach sheds some light on language change. It is proposed that language change has to do with the PF visibility of the configurations that formal features project (so parametric settings are a matter of location). It is claimed that the manifestation of the Romance future tenses is either morphological or periphrastic, depending on the visibility of the relevant syntactic chain of functional heads -T(ense), Asp(ect). A basic claim in this argumentation is that the derivation may start either from the relevant formal feature of the lexical category involved in the derivation ( $\mathrm{V}$, in the derivation of future tenses), or from the formal feature of the higher functional head involved in the derivation ( $T$, in the case of the future tenses). The derivation of the Portuguese periphrastic futures belong to the former type, while the derivation of the morphological futures belong to the latter.

The paper is organized as follows. Section 1 identifies three morphological types of past participles in Portuguese. Section 2 argues that the same configuration of abstract features underlies these three types of formation and leads to participial interpretation. It is claimed that the facts examined favor a theoretical framework that incorporates the thesis of isomorphism between expression and content at an abstract level where the notion of formal feature does not match the notion of morphosyntactic feature. Section 3 analyzes the diachronic stages in the development of the Romance future tenses and indicates how this development may be accounted for. The paper closes with a brief summary of the proposal, in Section 4. 


\section{The derivation of Portuguese past participles}

\subsection{Long and short forms}

Portuguese morphology derives non-root-stressed and root-stressed past participles. The non-root-stressed form is longer than the rootstressed form, because it overtly manifests a verb theme vowel (TV), which necessarily bears the main word-stress. ${ }^{1}$ Some verbs only allow one of these forms, others allow both, as illustrated in (1):

(1) a. Long Form Only:

começ-a-r ('begin'):

mov-e-r ('move'):

começ-a-do

sorr-i-r ('smile'):

mov-i-do

sorr-i-do

b. Short Form Only:

diz-e-r ('say'):

di-to

escrever ('write'):

escri-to

cobr-i-r ('cover'):

cober-to

v-i-r ('come'):

vin-do

c. Long and Short Forms:

expuls-a-r ('expel'): expuls-a-do / expuls-o

peg-a-r ('catch'):

peg-a-do / peg-o

prend-e-r ('bind', 'arrest'): prend-i-do / pre-so

suspend-e-r ('hang', 'interrupt'): suspend-i-do / suspen-so

exprim-i-r ('express'):

exprim-i-do / expre-sso

imprim-i-r ('imprint'):

imprim-i-do / impre-sso

The double participles in (1c) are of the kind called 'near doublets' by Kroch (1994). They are 'near' doublets because the two members of each pair differ in meaning (see next section) and in grammatical

1 This generalization holds without exception for forms of 1st conjugation. For 2nd and 3rd conjugations, there is sometimes no means of comparison, given the morphological unavailability of the long form (pôr: posto 'put'; ver: visto 'seen'; vir: vindo 'come'). For other verbs, with a "regular" form that is ungrammatical in standard Portuguese but grammatical in some dialects (cf. fn. 3), both forms have the same number of syllables and phonemes (abrir: aberto / abrido 'openned'; cobrir: coberto / cobrido 'covered'). 
properties. ${ }^{2}$ This paper will not try to investigate the theoretical status of the doublets. Our main concern will be the following issue: How is it possible for a language to arrive at the same grammatical semantic interpretation, namely, participial interpretation, from different types of morphological formation? Tbere are in fact three different types of past participle morphological formation in Portuguese, as I will try to show in section 1.3, after having demonstrated, in the next section, that the long and short forms have autonomous derivations.

\subsection{Autonomous derivations}

There is empirical evidence that the two types of participles (long and short) have independent derivations, so the short-form participles (traditionally called irregular) cannot be analyzed as reduced forms of the corresponding long participles (traditionally called regular). First of all, in the case of the near doublets, the two forms have specialized meanings, so, even when the long form is older and the short form more recent, they cannot have a derivational relationship. This seems to be the case for elegido / eleito ('elected'). As noted by Said Ali (1966), elegido seems to have been the common form in archaic Portuguese, and was supplanted by the Latinate form eleito, which entered into the language as an erudite creation of Renaissance writers, though both coexisted in Renaissance literary language. In present-day Portuguese, elegido has a very specific use as a verbal participle, restricted to contexts in which the agentivity of the process is emphasized, as in (2b), while eleito preserves its verbal interpretation in a wide variety of contexts and has an interpretation that has to do only with the result of the process, as in $(2 a)$ :

\footnotetext{
2 In oral Brazilian Portuguese there is a tendency to the formation of innovative short forms, leading to genuine doublets, as in comprado / compro (Ele já tinha comprado / compro o carro 'he had already bought the car'). These short forms are highly marked, sometimes causing laughter. It is as if their production were a slip of the tongue - a formation intended as a past participle by the speaker, but not interpreted as such by the hearer. These formations do not arise through dialect and language contact, but are confined to register variation. Among the stable doublets, the pairs aceitado / aceito (accepted), entregado / entregue ('delivered'), ganhado/ganho ('won'), gastado / gasto ('spent'), pagado / pago ('paid'), pegado / pego ('caught') are very close to genuine doublets. However, the preference for the use of the short form with passives shows that in fact they are not genuine doublets. On the theoretical issues related to doublets, see Kroch (1994).
} 
(2) a. Ter sido eleito foi bom.

(to) have been elected was good; Having been elected was good (=without implicit agent)

b. Ter sido elegido foi bom.

(to) have been elected was good; Having been elected was good (=with implicit agent)

Second, as Said Ali pointed out, the hypothesis that one of these forms is derived from the other is invalidated by the fact that in some cases the short form is older and the long form more recent. I will refer to this as the 'linked derivation' hypothesis, in opposition to the 'autonomous derivation' hypothesis. In his examples (3), the short form either became obsolete or underwent a category shift, so that the long form is currently the only usual verb form of the participle:

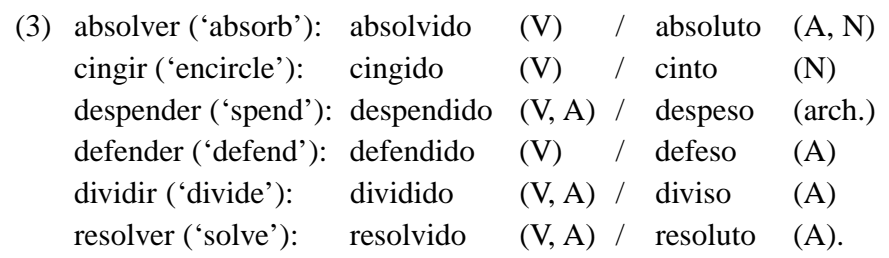

Furthermore, as also indicated by Said Ali, for some verbs Latin only generates the short form, while Portuguese only generates the long form:

(4) Latin: Only short forms motum ('moved') missum ('put') receptum ('received') victum ('beaten')

\author{
Portuguese: Only long forms \\ movido \\ metudo (arch.), metido \\ recebudo (arch.), recebido \\ vençudo, vivido (arch.), vencido
}

It seems then that Portuguese does not license the short forms for these roots, while Latin fails to license the long forms, which strongly favors the autonomous-derivation hypothesis. Finally, the linkedderivation hypothesis in untenable because in some cases the short form entered the language before the creation of the verb, and only subsequently became a part of the verb inflection. Said Ali cites the 
case of entregue ('delivered') first used as an adjective (ser entregue de alguma cousa; lit.: 'be delivered of something'), from which the verb entregar ('deliver') was created, the adjective then being used as a past participle as well.

\subsection{Three types of past participle formation}

The morphophonological shape of Portuguese past participles shows that there are three types of past participle formation in Portuguese, one for long forms and common to all conjugations, and two for short forms, one specific to first conjugation and the other specific to second and third conjugations. These three types share the presence of the string [stressedV $+\mathrm{C}+\mathrm{V}$ ], but differ with respect to its location within the word:

(5) Location of the string [stressedV $+\mathrm{C}+\mathrm{V}]$ in Portuguese PPs:
(A) $\left[[\ldots]_{\text {Root }}+[\right.$ stressedV $\left.+\mathrm{C}+\mathrm{V}]\right]$
(all conjugations)
(B) $\left[\left[\ldots[\operatorname{stressedV}(\ldots)]_{\text {Syllable }}\right]_{\text {Root }}+\mathrm{C}+\mathrm{V}\right]$
(2nd and 3rd
conjugations)
(C) $\left[\left[\ldots[\operatorname{stressedV}(\ldots)]_{\text {Syllable }}+\mathrm{C}\right]_{\text {Root }}+\mathrm{V}\right]$
(1st conjugation)

For the sake of simplicity, I will illustrate these three patterns with participles that allow a verbal interpretation. The pattern (5B) is only licensed by verbs of 2 nd and 3 rd conjugations, whether these verbs only take short forms, as in (6), or not, as in (7). The pattern (5C) is licensed by verbs of 1 st conjugation, and is illustrated in the list of 1 st conjugation participles in (7). The pattern (5A), typical of the majority of the verbs of the language, is illustrated by the long forms in (7), from all the three conjugations. ${ }^{3}$ The other verbs of the language only take long forms for the formation of verbal past participial.

\footnotetext{
3 Morphological derivations enlarge the inventory of these classes: descrever: descrito, refazer: refeito, transpor: transposto, prever: previsto, satisfazer: satisfeito; encobrir: encoberto; etc. The inventory presented in this paper corresponds to my own judgment about these forms; see Lobato (1999) for an explanation of the criteria used for the classification of these participles as verbs. Besides the diachronic variation already noted by Said Ali and mentioned above, there is variation in the use of the near doublets in contemporary language as well. C. Rodrigues (p.c.) has brought to my notice the normal use of the long forms abrido (V) and escrivido (V, A) in Minas Gerais, in the region of Matutina, São Gotardo and Tiros
} 
(6) Single Irregular Participles:

2nd conjugation:

dizer ('say'): dito, escrever ('write'): escrito, fazer ('do'): feito, pôr

(put'):

posto, ver ('see'): visto.

3rd conjugation:

abrir ('open'): aberto, cobrir ('cover'): coberto, vir ('come'): vindo.

(7) Double Participles:

1st conjugation:

aceitar ('accept'): aceitado / aceito, cegar ('blind'): cegado / cego, circuncidar ('circumcise'): circuncidado / cincunciso, descalçar ('take off the shoes'): descalçado / descalço, despertar ('wake up'): despertado / desperto, dispersar ('disperse'): dispersado / disperso, entregar ('deliver'): entregado / entregue, enxugar ('dry'): enxugado / enxuto, expressar ('express'): expressado / expresso, expulsar ('expel'): expulsado / expulso, findar ('end'): findado / findo, fixar ('fix'): fixado / fixo, fritar ('fry'): fritado / frito, ganhar ('win'): ganhado / ganho, gastar ('spend'): gastado / gasto, isentar ('exempt'): isentado / isento, juntar ('join'): juntado / junto, libertar ('liberate'): libertado / liberto, limpar ('clean'): limpado / limpo, livrar ('free'): livrado / livre, manifestar ('manifest'): manifestado / manifesto, matar ('kill'): matado / morto, murchar ('wilt'): murchado / murcho, ocultar ('conceal'): ocultado / oculto, pagar ('pay'): pagado / pago, pegar ('catch'): pegado / pego, quitar (pay off (a debt), release (from an obligation)): quitado / quite, salvar ('save'): salvado / salvo, secar ('dry'): secado / seco, segurar ('hold'): segurado / seguro, sepultar ('bury'): sepultado / sepulto, soltar ('loosen', 'set free'): soltado / solto, sujeitar ('subject') : sujeitado / sujeito, suspeitar ('suspect') : suspeitado / suspeito, vagar ('roam'): vagado / vago.

2nd conjugation:

acender ('light'): acendido / aceso, benzer ('bless'): benzido / bento, eleger ('elect'): elegido / eleito, envolver ('envelop', 'wrap'): envolvido / envolto, incorrer ('incur'): incorrido / incurso, morrer ('die'): morrido / morto, prender ('arrest'): prendido / preso, revolver ('revolve'): revolvido / revolto, suspender ('hang', 'interrupt'): suspendido / suspenso.

(Triângulo Mineiro), where the short form aberto also exists, but as an adjectival form (porta aberta 'open door'). The long form is also the current form for eleger in this region. She specifies that this variety of the language was heavily influenced by the variety of Portuguese spoken in Madeira Island, and is idiosyncratic also in the use of ' $b$ ' for ' $v$ ' (e.g. bassoura 'broom' and trabesseiro 'pillow' for vassoura and travesseiro). Besides the geographic variation, in oral Brazilian Portuguese the occurrence of short forms is attested for verbs that in the standard language only take the long form (comprar: comprado / compro, falar: falado / falo, etc.), as pointed out in fn. 2. 


\begin{abstract}
3rd conjugation:
emergir ('emerge'): emergido / emerso, exprimir ('express'): exprimido / expresso, extinguir ('extinguish'): extinguido / extinto, frigir ('fry'): frigido / frito, imergir ('immerse'): imergido / imerso, imprimir ('print', 'imprint'): imprimido / impresso, incluir ('include'): incluído / incluso, inserir ('insert'): inserido / inserto, restringir ('restrict'): restringido / restrito, submergir ('submerge'): submergido / submerso, tingir ('dye'): tingido / tinto.
\end{abstract}

In (8)-(9) the three patterns in (6) are presented with specific information about the nature of the segments of the string [stressedV + $\mathrm{C}+\mathrm{V}]$ :

(i) In the long forms, each of these segments performs a grammatical function within the word: they are interpreted as [stressed verbal T(heme) $\mathrm{V}$ (owel) + suffixal $-d+$ nominal TV]. This sequence of grammatical elements is realized to the right of the verb root, as in (8).

(ii) As for the short forms, what makes them different from the long forms is that now some of the segments of that string are necessarily found within the root, which means that they are integrated in the lexical part of the word. In all the short forms the stressed $\mathrm{V}$ is a part of the root: it is precisely the vowel of the rightmost syllable of the root, and, in the case of two contiguous nonconsonants in that syllable, it is the one to the left (e.g.: a-cei-to, e-lei-to). A consonant may follow this vowel (e.g.: desperto, gasto). The difference between the two types of short forms concerns the role played by $\mathrm{C}$ :

(iia) In the short forms of second and third conjugations the two segments $[\mathrm{C}+\mathrm{V}]$ perform a grammatical function: [suffixal $-t$ or $-\mathrm{s}+$ nominal TV]. This sequence of two grammatical elements is realized to the right of the root, as in (9a).

(iib) In the short forms of first conjugation both the stressed $\mathrm{V}$ and $\mathrm{C}$ are found within the root. Thus, in this case it is only the last V, interpreted as the [nominal TV], that has a grammatical function. It is then only this $\mathrm{V}$ that is realized to the right of the root, as in (9b).

(8) Long-form participial formation:

(1st, 2nd and 3rd conjugations)

$[$ Root $]+[$ stressed verbal TV $]+[-d]+[$ nominal TV $]$. 
(9) Short-form participial formations:

a. 2nd and 3rd conjugations:

$\left[\left[\ldots[\text { Stressed } V(\ldots)]_{\text {Syllable }}\right]_{\text {Root }}+[-t\right.$ or $-s]+[$ nominal TV $\left.]\right]$ or

$\left[\left[\ldots[\text { Stressed V + Nasal }]_{\text {Syllable }}\right]_{\text {Root }}+[-d]+[\right.$ nominal TV $\left.]\right]$

b. 1 st conjugation: ${ }^{4}$

$\left[\left[\ldots[\text { Stressed V }(\ldots)]_{\text {Syllable }}+\mathrm{C} \text { different from } d\right]_{\text {Root }}+[\right.$ nominal TV $\left.]\right]$ or $\left[\left[\ldots\left[\text { Stressed } \mathrm{V}+\mathrm{Nasal}_{\text {Syllable }}+d\right]_{\text {Root }}+[\right.\right.$ nominal TV $\left.]\right]$.

Two facts make it clear that the string [stressedV $+\mathrm{C}+\mathrm{V}$ ], shared by the three types of formation, is the manifestation of underlying information crucial for participial interpretation. One of them is the grammatical status of the three segments of this string in the long-forms - verbal TV, suffix and nominal TV: since these three parts of the string bear grammatical information, they bear information necessary to the building of the participial interpretation. Therefore, this information has to occur with any lexical item with past participial interpretation. The other fact is the occurrence of this same string in the short forms, even though at different locations of the morphological structure: since in the long forms the three segments of the string bear information necessary to the building of the participial interpretation, participial interpretation requires the presence of well-defined information; given this requirement,

4 There are two 'exceptions' to the generalization that in the case of short forms of first conjugation the element $\mathrm{C}$ corresponds to the last consonant of the root: circuncid-ar: circunciso, enxug-ar : enxuto. In the theory of grammar we are suggesting, the $\mathrm{C}$ in these two examples is the form of underlying information, and the underlying information is projected according to the intended semantic interpretation, due to the isomorphism principle. Thus, these examples are not exceptions. The fact that the consonant is then overtly realized as 's' (phonetically $[\mathrm{z}]$ ) and ' $\mathrm{t}$ ', which are the forms of $\mathrm{C}$ in the participial suffixes of second and third conjugations is a piece of evidence in favor of this proposal, although we do not provide a full explanation. Concerning circunciso, notice that it is a general fact for short forms that the segment $\mathrm{C}$ is only realized as ' $\mathrm{d}$ ' when immediately preceded by a nasal (e.g. findar: findo). Given that generalization, the non-generation of the form circuncido does not seem fortuitous (differently from findar) in circuncidar, although the root also ends in $-d$, there is no nasal immediately preceding it. In the framework I am suggesting, phonemes are built with formal features. We may then suppose that in the derivation of the long forms the underlying position of segment $\mathrm{C}$ has a configuration of features that matches, at least in part, the configuration of the segment ' $d$ '. In the short forms, in contrast, the underlying configuration of features would only match this configuration when immediately preceded by nasality. And this is because nasality would likewise be the form of a certain underlying configuration involving formal features. Thus, in the short forms the conjunction of these two configurations (nasality $+\mathrm{C}$ ) is a necessary condition for the overt manifestation of $\mathrm{C}$ as ' $d$ '. This would explain why the consonant ' $d$ ' is not realized in those short forms: the necessary configuration is not present. 
it is reasonable to think that the occurrence of the same string in the short forms manifests the presence of the same type of underlying information.

\section{A feature-based proposal}

\subsection{In favor of feature-based morphological derivations}

The facts presented in Section 1 and summarized in (5), (8)-(9) show that interpretation of a given Portuguese lexical item as a past participle depends on information underlying the segments of the string $[$ stressedV $+\mathrm{C}+\mathrm{V}]$. Thus, the difference between the three observed types of formation relates to the location, within the morphological configuration of the word, of the information relevant to participial interpretation. It is important to keep in mind that this paper is concerned with what these forms have in common and accounts for their sharing of the same type of grammatical semantic interpretation - namely past participle interpretation - in spite of their morphophonological differences. There are also semantic differences among the different types of morphological formation (categorial and thematic differences, for instance), which must be accounted for, but they are beyond the scope of this paper. ${ }^{5}$

It is very reasonable to think that the information that is relevant to participial interpretation is expressed in the form of features and, more precisely, as a configuration of features. First of all, as I have already pointed out, the fact that the long form is derived with the manifestation of three segments of the grammatical type is evidence that these three segments are the manifestation of information necessary for past participle interpretation. These segments correlate here with a string of three grammatical constituents, and there with a string of either one or two grammatical constituents, the other segment(s) being found within the root. However, the same string occurs in the three types of formation. This means that the grammatical semantic information required for past participle interpretation is found in different constituents of the word, depending on the type of formation involved. Since the same type of

5 On the categorial and thematic issues related to past participles, see Pires (1996). 
information, needed for past participle interpretation, is found in different constituents of the word, these different constituents obviously bear the same type of information. Thus, for instance, the information that underlies the stressed root vowel in the short formations - and which is relevant for the interpretation involved - underlies the verb TV in the long formation. This conclusion is reinforced by the hypothesis of this paper that a certain configuration of formal features underlies the occurrence of stress; if that is so, the stressed root vowel of the short formations and the TV of the long formation share the same type of formal feature, relevant for stress realization. Therefore, the root of the short formation and the TV of the long formation bear the same underlying information, crucial for past participle interpretation. In turn, since different constituents bear the same type of information, it must be true that this information is expressed as discrete elementary units.

The same has to be true with respect to the relevant consonant: in the long forms, and in the short forms of the 2nd and 3rd conjugations, this consonant is a suffix, while in the short forms of the 1st conjugation it is within the root. Since a given piece of information, needed for participial interpretation, is found in the relevant consonant (here a suffix, there a part of the root), it is necessarily true that the suffix and the relevant roots bear the same type of information in the underlying, abstract structure. Since the same type of information underlies the relevant suffix and roots, this information has the form of discrete, elementary units.

These units are then discrete in the sense that they have their individuality, so that on the one hand they are not continuous and on the other hand they are autonomous, in some sense, of particular morphemes or morphs. In linguistic literature, the notion of features applies to basic, discrete units used in the construction of higher objects; e.g. the properties [Consonant] and [Coronal]; [Human] and [Animate]. Accepting this type of characterization, it seems appropriate to say that the information required for the interpretation of past participle is expressed in the form of features.

Furthermore, there is empirical evidence that these elementary units have the theoretical status of features. One such piece of evidence is found in the change in stress placement that took place in the verb system, from Latin to Portuguese. For instance, Latin, but not Portuguese, licenses root-stressed participles with overt verb TV. In Portuguese, if the past 
participle bears a verbal TV, the TV must bear main stress. Those forms were licensed in Latin for the 2nd and 3rd conjugations, as illustrated in (10), where the underlining marks the stressed syllable:

(10) Stress Differences between Latin and Portuguese Past Participles:

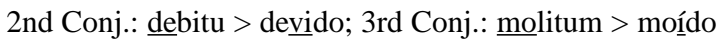

However, as (11)-(12) show, the change relating to the requirement of stress in the verb TV was not restricted to past participles. In fact, this change evolved in all infinitive and past forms, but only in the past forms among the inflected forms. ${ }^{6}$ In Latin, in the past tense inflected forms (whether perfective or imperfective), word stress is borne by the verb TV or by a mood-tense suffix, this suffix being the rightmost moodtense suffix of the word in the linear order (or the higher one in terms of the c-command relations among the morphological constituents of the word), in the case of two suffixes of this kind within the word:

\begin{tabular}{ccc}
\multicolumn{2}{c}{ Latin Verb Past Forms, 1st Conjugation, 1P } \\
Imperfect & Past Perfect & Pluperfect \\
Mood-TenseSuffix & VTV & Mood-TenseSuffix \\
amabamus amaremus & amavimus & amavengamus
\end{tabular}

In Portuguese, in the past inflected forms stress is always borne by the TV, for all persons and all conjugations, so the Latin data in (11) correspond to the Portuguese data in (12):

\begin{tabular}{ccc}
\multicolumn{2}{c}{ Portuguese Verb Past Forms, 1st Conjugation, 1P } \\
Imperfect & Past Perfect & Pluperfect \\
VTV & VTV & VTV \\
amávamos amássemos & amamos & amáramos
\end{tabular}

Therefore, where the stress was borne by the verb TV in Latin past forms, its placement did not change in Portuguese; but where it was placed elsewhere, it did, resulting in a new pattern of stress assignment in Portuguese past tenses. As mentioned above, this type of change only took place in past tenses, among the inflected forms. For present tenses,

6 See Wohlmuth 's (1978) work on the irregular past participle in Hispano-Romance. 
Portuguese maintains the general Latin stress pattern of distinguishing the stressed segment according to grammatical person - with stress on the TV for first and second plural and on the root for all other persons. Thus, Latin: amo, amas, amat, amamus, amatis, amant, and Portuguese: amo, amas, ama, amamos, amais, amam. As for the future tense, a totally new pattern was created, with stress on a suffix: amarei, amarás, amará, amaremos, amareis, amarão. ${ }^{7}$ This contrasts with the Latin pattern of stressing either the verb TV or the root for the imperfect future - amabo, amabis, amabit, amabimus, amabitis, amabunt; audiam, a audies, a audiet, audiemus, audietis, audient. Of course, I am not implying that there was a stress shift here, since the Portuguese future represents a new type of morphological formation, created in the recent history of Romance. What I am saying is that this new creation as well as the loss of the Latin-type future formation are anyway related to stress. It is as if, in the inflected forms, the change were oriented by the presence / absence of the properties underlying past tense interpretation, but in a mutual relationship between expression and content (i.e., between the phonological and semantic representations): past tense interpretation requires the presence of these properties, and the presence of these properties compulsorily attracts stress; the change consisted in the visibility of these properties solely in the position of the verb TV, with the result that stress became necessary in this position, for this interpretation; in turn, the presence of stress in the verb TV of inflected forms is an overt sign of the underlying presence of these properties; thus, where this interpretation does not pertain, these properties are absent, as is stress, hence the loss of the Latin type of future formation. Given this analysis, I conclude that in the present tense forms with stress in the verb TV (1st and 2nd person plural), the person interpretation creates a configuration of features in which those properties, necessary for past tense interpretation, are again visible for phonological interpretation in the position of the verb TV. Similarly, the infinitive forms are presumably underpinned by those properties that attract stress to the verb TV.

\footnotetext{
7 Bisol (1994) analyzes Portuguese future forms as having two main stresses assigned in the course of the derivation, one on the VTV and the other on the suffix; only the stress on the VTV remains at the end of the derivation, due to Portuguese restriction on sequences of two main stresses. Mateus (1990: 358) argues that the stress occurs in the first vowel of "the temporal morpheme" ( $\mathrm{re} / \mathrm{ra}$ for the present future and ria for the preterit future).
} 
The fact, then, is that at some underlying level there is a crucial linguistic difference between past, present and future, in the case of the inflected forms, and this difference is relevant for stress placement in Portuguese. Let us assume that tense is represented by means of features. I have just observed that there is a relationship between the location of stress and the temporal information. It therefore follows that the location of stress is related to the location of certain features, namely features associated with temporal information. Furthermore, accepting that a given piece of information borne by the root in short forms is also borne by the verb TV in long forms, then that also is information represented in the form of features. Finally, the fact that in the architecture of the mind / brain there is mutual interaction among the different conceptual and sensorimotor systems also requires the overall use of the same type of basic unit; thus, given these legibility conditions (or bare output conditions; see Chomsky 1995, 1998), the information underlying each segment of the string [stressed $\mathrm{V}+\mathrm{C}+\mathrm{V}$ ], and not only the information underlying the stressed $\mathrm{V}$, takes the form of features.

Finally, the configurational status of the relevant features is clear in the fact that participial interpretation depends on a string of segments $[$ stressedV $+\mathrm{C}+\mathrm{V}]-$ rather than on a unitary segment. This linear string corresponds to a given hierarchical configuration in structural terms, which is the mirror image of the linear order (Baker's Mirror Principle). It is easy to see how this works in the phonological representation, because of the overt phonetic manifestation of this string in Portuguese. How do I know that there is a hierarchical configuration also at the formal level? I know it, first of all, because this string corresponds to part of the syllabic structure. The facts examined in Section 1.3 support this conclusion. The three types of participial formation show that the phonological content of the segments of the string [stressed $\mathrm{V}+\mathrm{C}+\mathrm{V}$ ] does not matter, since the segments get varied forms. What matters is their $\mathrm{C}, \mathrm{V}$ nature. Thus, these segments relate to the $\mathrm{C}, \mathrm{V}$ structure of the word. Therefore, since the $\mathrm{C}, \mathrm{V}$ structure is the syllabic structure, they relate to the syllabic structure. Thus they belong to the non-segmental PF structure and are then assigned a structural interpretation. The requirement of stress on the leftmost vowel of the string supports this conclusion: the segments of that string indeed seem to belong to PF structure. However, as mentioned, this information has a semantic correlate of the grammatical type. I take this to indicate that there is isomorphism between expression and content at an abstract 
structural level: assuming that there is this type of isomorphism, the configuration related to the string [stressedV $+\mathrm{C}+\mathrm{V}$ ] likewise belongs to the level of grammatical semantic structure. In syntax, this configuration drives grammatical semantic interpretation. We now have a possible explanation for the fact that Portuguese past participles have the right information in an underlying location that parallels its location in the phonological representation: this information is information of syntactic structure that is visible to phonology in Portuguese, driving spelling out.

Of course, I have not accounted for stress placement, nor for the relationship between the hierarchical configuration and the stress placement. This is a complex issue that I treat elsewhere (Lobato 1998, In preparation).

\subsection{Towards a theory of grammar with formal features}

The analysis above suggests that the formula [stressed $\mathrm{V}+\mathrm{C}+\mathrm{V}$ ] is a 'template' that can be associated with a past participle by aligning the rightmost vowel of the formula with the final vowel of the participle; the consonant with the suffix or the last consonant of the root, and the leftmost vowel with the theme vowel or the vowel in the rightmost syllable of the root (or the vowel to the left in this syllable, in the case of two contiguous nonconsonants in this syllable); stress goes on the vowel that matches the position of the leftmost vowel of the formula, whether this is the TV or the root vowel. There is, therefore, a direct and necessary correlation between the morphophonological form of these lexical items and their grammatical interpretation. This correlation supports the view that the syllabic, prosodic and morphological configurations are built with the same kind of features, which are also accessible to grammatical interpretation and phonetic realization, as well as the hypothesis that the phonological and semantic representations are isomorphic at the grammatical semantic structure.

First, if it is possible to have a template associated with the participial interpretation, with a well defined variation in the location of this template within the word, it is because each segment of the template is the form for a very precise abstract type of information leading to the participial interpretation; and there is variation in the location of the template within 
the word because these abstract pieces of information are found in different locations of the word, according to the root under consideration. This hypothesis is compatible with a compositional view of participial interpretation. However, the morphological structure is highly relevant to semantic interpretation because the presence of the formula is not a sufficient condition for participial interpretation: verb inflections such as amo '(I) love', which overtly manifests the phonological string [stressedV+C+V], but has the morphological structure [Root $+\varnothing+\varnothing+\mathrm{o}]$, with null phonological realization for the TV and tense-mood, and overt realization for person-number, are not interpreted as past participles (so amo allows the interpretation 'I love' but not the participial interpretation). ${ }^{8}$ So, for the participial interpretation to obtain, there must be a correlation between this phonological string and the verbal morphological structure, according to the morphological types we have already pointed out. Thus, what is relevant for the participial interpretation is not exactly a string of three independent and isolated bits of information, but rather a given structure involving that information and defined in morphological terms. Furthermore, these bits of information activate semantic interpretation. Under the assumptions of this paper, this structure is built with formal features.

Further, we have already argued that the string [stressed $\mathrm{V}+\mathrm{C}+\mathrm{V}]$ is absolutely necessary for participial interpretation, and reflects part of the syllabic and prosodic structure of the word. This fact favors the hypothesis that the same feature configuration underlies the grammatical and phonological organizations, as well as the grammatical and phonological interpretations. On the one hand, the mutual, necessary correlation between the presence of this string and the participial interpretation supports the view that the configuration of features that the grammatical semantic interpretation reads is exactly the same configuration read by the syllabic and prosodic phonological interpretation. On the other hand, if this is possible, it is because the computational system generates a single formal structure that is analyzed from two different standpoints: the standpoints of non-segmental phonology and grammatical semantics.

\footnotetext{
8 Notice that the short-form participles of the 1st conjugation are homonyms of the forms of 1 st person singular of the indicative present: pago 'paid' or '(I) pay'. This is only a surface identity, since their morphological structures are different. See also fn. 2.
} 
These conclusions are compatible with the claim that there is isomorphism between expression and content, in the sense that there is a formal structure common to the PF and semantic systems, but strictly at the non-substantive level: at the substantive level, due to the addition of substantive semantic and phonological information, there cannot be isomorphism.

In this discussion, it remains to be demonstrated that syntactic constructions use abstract features of the same type used in morphology, phonology and semantics. The morphological and syntactic nature of inflection provides a line of argumentation in favor of this proposal: (a) it is an empirical fact in Portuguese that the nominal TV is a necessary segment of the phonological template associated with participial interpretation; TVs, in general, are the phonetic realization of formal features; (b) it is also an empirical fact in Portuguese that the nominal TVs are inflectional marks in the passive participles, as in Os livros foram lidos (the books-MP were read-MP), As revistas foram lidas (the magazines-FP were read-FP), and it is a generality in languages that inflectional properties are elements of the syntactic construction, as in the subject-predicate agreement relation; (c) therefore, assuming that in the morphological construction the nominal TVs are the spelling out of formal features, given that nominal TVs are used as inflectional marks in the syntactic construction, then the features used in the morphological construction are of the same type as the features used in the syntactic construction - in both cases, they are formal features. ${ }^{9}$ A different line of argumentation may be constructed on the basis of the thematic information in the past participles. As noticed, there is a thematic difference between eleito and elegido, in the sense that the long form, but not the short form, expresses the existence of an implicit agent:

(2) a. Ter sido eleito foi bom.

(to) have been elected was good; Having been elected was good (=without implicit agent)

b. Ter sido elegido foi bom.

(to) have been elected was good; Having been elected was good (=with implicit agent)

9 This is what one expects, under the assumption that the formation of lexical items "is subject to principles known to be operative in syntax", as pointed out by Hale \& Keyser (1993). 
The same thematic difference is found regarding certain verbs of the 1st conjugation:
a. despertado / desperto
b. manifestado / manifesto

I have argued that each segment of the participial template is a form of specific underlying information, and have treated this abstract information as formal features. What distinguishes the long forms in (13) from the respective short forms is the manifestation of both the VTV and the suffixal consonant: despert(ad)o; manifest $(a d) o$. Therefore, given that the difference in the spelling out of formal features in the participial formation correlates to a difference in the thematic information of the participle, the natural conclusion is that formal features are also involved in the thematic information of the lexical item. Since thematic information is used in syntactic construction, the formal features must be basic elements of the syntactic construction as well.

\section{Language change}

The last section of this paper has already presented empirical evidence of the role of formal features in linguistic change: the case of change in stress placement in the verb system, from Latin to Portuguese. I have pointed out that this change was directional, in the sense that it selectively took place in the inflected forms according to tense distinctions: there was a change towards necessarily placing stress in the VTV in past tenses and necessarily avoiding it in this position in the future tense forms, so in the cases in which these two intended situations already existed, there was no change; in the present tenses there was not any change either. Thus, the change was "directional" in that it was guided by some abstract property underlying temporal interpretation. Accepting the view that present-past-future are conceptual constructs, compositionally derived from the use of features, I must conclude that the change in stress placement from Latin to Portuguese relates to some use of features. Since only formal features are simultaneously visible to phonological and semantic interpretation, from the fact that the information underlying tense is visible to stress I must also conclude that this information is encapsulated under the guise of formal features 
(after all, it is information visible to the phonological component, as we know from the Portuguese facts concerning stress placement, and visible to the semantic component, as we know from the temporal interpretation). This conclusion is reinforced by the property of formal features of being the only features in language actively involved in the building of structures: if this is indeed so, then the properties underlying the building of past participles are formal features.

In this section I want to argue that language change has to do with the visibility to the PF system of the configurations of formal features relevant to grammatical semantic interpretation. Assuming that SpellOut depends on the inherent information of functional heads, parametric setting relates to the PF role of the functional heads. Taking the information of the functional heads to be formal features, language change relates to the PF role of the formal features of the functional heads. Under the perspective of this paper, language change reduces to visibility to $\mathrm{PF}$ of the underlying configurations of formal features in the abstract grammatical semantic structure.

In some cases, it is clear that parametric setting is a matter of choosing either the lexical information or the information structure as the layer, or plane, where the formal features are visible to phonology. This is the type of change that seems to have occurred in the evolution from Latin to Portuguese, with respect to stress. In the Latin verbal system, the stress configuration is read by the PF system in the lexical network of features projected from the root for the building of the word grammatical semantic interpretation. Evidence of that is the relevance of the conjugation for stress placement in the past tenses in Latin: the pertinence to a specific conjugation is a totally idiosyncratic fact depending solely on the root. In Portuguese, the stress configuration is likewise read by the PF system at the formal level, but in the network of features provided by the word morphological structure. Evidence of that is the fact that only the verbal TV position matters for stress placement in Portuguese past tenses, so the information about the occupant of this position is totally irrelevant, for this purpose. Thus, the change from Latin to Portuguese, relating to stress, was a change concerning the location of the visibility to the PF system of a certain configuration of features: visibility in the lexical network, in Latin; visibility in the information structure, in Portuguese. 
The proposal that parametric setting is a matter of the phonological role of the formal features of the functional heads is highly favored by the analysis of the diachronic evolution of the future tenses, from Latin to Portuguese. So far, the comparison between Latin and Portuguese in this paper has focused on the contrast in stress placement between Classical Latin and Portuguese. However, it is a well-known fact that there were intermediate stages in the diachronic development from Classical Latin to Romance languages, as illustrated by the evolution of the future tenses of most of the modern Romance languages (future and conditional, or present future and preterit future in the grammatical literature). According to the traditional view on this subject, the future endings of these Romance languages are the direct development of the Latin periphrastic construction Infinitive + habere ('have'), through specific stages. Roberts (2000) points out two stages: (A) habere, a full lexical verb in Classical Latin, was reanalyzed as a future auxiliary, comparable to will and shall in Modern English - it became athematic and was used to mark purely temporal content (amare habeo 'love have+1stSing'); (B) the auxiliary habere, an autonomous word, was reanalyzed as a syntactic affix. This development was then clearly a process of grammaticalization. I will try to show now that, although this is not so clear at prima facie, in this case too, the distinction between visibility in the lexical network and visibility in the information structure is likewise involved.

Grammaticalization has been commonly analyzed as a case of change from lexical to grammatical material. Roberts \& Roussou (1999, Forthcoming) and Roberts (2000) try to account for this intuition in a generative framework. Roberts and Roussou claim that grammaticalization is a process of loss of movement from a lexical head to a functional head, and direct merge of the lexical material in that position. This is then a process of reanalysis of lexical heads as functional heads. They also hold that grammaticalization is a case of reanalysis involving structural simplification (see Roberts \& Roussou 1999, for instance). Due to limitations of space, I will not give a detailed presentation of Roberts and Roussou's proposal on grammaticalization here. I remit the reader to the references above and now turn to the suggestion of an alternative analysis. This alternative analysis conforms to the basic idea of this paper that there is a formal structure generated by the computational system and shared by the non-substantive phonological and semantic components. In this alternative proposal, 
every case of linguistic change is a case of change of the location, in the grammatical semantic structure, where a certain configuration of formal features - relevant for grammatical semantic interpretation - is visible to the modules dealing with linearization of the information (PF modules, taking them to include the module of word formation). Thus, in this new approach, language change relates to the visibility to the PF system, in the underlying formal structure, of the abstract configurations relevant to grammatical semantic interpretation. I will conclude that it is always the case that the change of location relates to a change in the plane where the formal features configurations are accessed - either L(exical) plane (plane of the lexical information), or G(rammatical) plane (plane of the lexical information structure). The argumentation here will be restricted to futurity interpretation.

Let us first clarify three fundamental assumptions of our proposal, concerning future tense interpretation. First, the auxiliary of the periphrastic construction does not represent the overt realization of futurity. This means that, in the Latin formation infinitive + habere, habere is not the manifestation of the notion of futurity, just as 'ir' (go) is not, in the Portuguese future construction 'ir' + infinitive. As clearly demonstrated by Benveniste (1965), the temporal interpretation of periphrastic constructions comes from different aspects of these constructions (lexical information of each verb, grammatical information of each verb, syntactic structure). Second, tense interpretation is a mental construct, compositionally derived with the use of abstract features. Thus, the notion of futurity correlates with a well defined configuration of formal features. This compositional property is what is expected, given that temporal interpretation comes from different parts of a construction. Third, since there is a welldefined configuration of formal features involved in the semantic interpretation of futurity, this configuration has to underlie the morphological future tense formations as well. I will come to this assertion below.

Accepting that the notion of futurity correlates with a certain configuration of formal features, the changes that effectively took place in the expression of futurity in Romance languages cannot be seen as having affected this structural configuration. Given the assumptions of the theory of grammar expounded in this paper, the only possible, natural explanation is in terms of visibility to the PF system of the formal 
feature configuration related to futurity interpretation. ${ }^{10}$ This eliminates the possibility of taking grammaticalization as a case of structural simplification.

Let us consider the stages of the change, borrowing from Roberts $\&$ Roussou's (Forthcoming) analysis and adding the facts about Classical Latin and present-day Portuguese. The addition of facts from Classical Latin gives us: (I) Classical Latin: morphological formation with use of special endings incorporated in the verb form; these endings inform about grammatical person, temporal distinctions, thematic function of the subject ('amabo'); (II) Imperial Latin: syntactic formation with use of an autonomous word (the auxiliary verb) that bears the inflectional marks ('amare habeo' 'love have+1stSing'); this formation gradually spread to different types of verbs, with loss of the active / deponent distinction; (III) Romance: morphological formation with use of a grammatical affix incorporated in the verb form; the verbal morphology does not overtly realize the thematic function of the subject ('amarei', in Portuguese). The subsequent (and much more recent) stage represents a return to a periphrastic construction. At this stage, French and Portuguese, for instance, use the auxiliaries 'aller' and 'ir' (go), respectively., as the autonomous word generated by the future tense formation. Keeping to the Portuguese case for the simplicity of the subsequent argumentation, we have: (IV): Modern Portuguese: syntactic formation with use of 'ir' as the autonomous word that bears the inflectional marks (vou amar 'go+1stSing love'). ${ }^{11}$ Thus, stage (IV) is similar to stage (II) in that both manifest the notion of futuriry as a syntactic formation with inflection realized by an autonomous word. However, these two cases differ in two significant respects: choice of the auxiliary ('ir' vs habere) and word order (Aux+Inf vs. Inf+Aux). In current-day Brazilian Portuguese (IV) is clearly the only futurity

\footnotetext{
10 Observe that in this approach it is not appropriate to say that the future surface construction of a given stage is the direct development of the future surface construction of the previous stage. For instance, we could not say that the Romance future endings are the direct development of the Latin verb habere; rather, both the Latin verb habere and the Romance future endings share common underlying properties.

11 At present, it is not possible to date the beginning of stage (IV). It is clear, however, from Mattos e Silva's (1989) work, that at the end of the 14th century the 'ir + infinitive' periphrasis was not yet purely temporal. Mattos e Silva (see p. 459) found only 13 occurrences of this periphrasis in a total of 17,429 occurrences of verb forms in her corpora from that century and in every case these few occurrences have a modal interpretation (intention).
} 
formation triggered by the PLD, since the morphological formation in (III) is acquired through teaching in schools. Therefore, since the more grammaticalized form of futurity is succeed by the less grammatized, if it is true that language change follows some 'direction', the cause of this direction is not grammaticalization, so some different type of motivation must be found.

In the approach sugggested in this paper, grammaticalization, like every other type of language change, has to do with the PF side of the grammatical semantic structures generated by the computational system. However, we have to take 'PF side' as including the word formation module. That is, we have there a PF system and not just phonology. Indeed, in each case of grammaticalization, a given construction relevant for grammatical semantic interpretation is involved and the issue is the morphological realization of this construction; in the case of the expression of futurity in Romance, realization either as an autonomous word, or as an affix. The change, in this case, then, relates to morphological manifestation of the underlying configuration of formal features - either as a one-word construction, or as a two-word construction. I have already observed that the same configuration of formal features underlying the periphrastic future formation must underlie the morphological formation, according to the approach propounded in this paper. An empirical piece of evidence in favor of this claim is found in the morphic structure of Portuguese morphological futures: they have a morphic structure that precisely mirrors the underlying syntactic formation. To demonstrate this, I will first consider the syntactic structure of the periphrastic formations and some related facts.

I have observed earlier in this paper that the change in stress placement, from Latin to Portuguese, took place in the inflected forms according to tense distinctions. I have also observed that the infinitive and past participle forms underwent the same type of change that evolved in the inflected past forms: change towards stress on the VTV. Let us take the traditional view on the distinction between inflected / uninflected verbal forms, and say that uninflected forms are aspectual forms and inflected forms are temporal forms. Under this view, the facts about stress placement that I have examined support the conclusion that tense and aspect are crucial functional heads for the occurrence of stress. Let us assume the strongest hypothesis about sentential structure: that up to 
TP this structure has only two functional heads - T(ense) and Asp(ect). Thus, a complete sentential structure of a verbal nature implies the following hierarchical organization: (TP, AspP, VP). The facts I have examined concerning the development of future tenses in Romance add a new consideration to the conclusion that $\mathrm{T}$ and Asp are crucial functional heads for the occurrence of stress: the importance of tense and aspect for word formation, with respect to verbs. Indeed, on the one hand, the morphological and periphrastic formations seem related to the tense / aspect distinction: in the morphological formation, there is word formation at the level of tense, and only at this level; in the periphrastic formation, there is word formation at both levels, tense (for the auxiliary) and aspect (for the main verb). On the other hand, main stress is clearly related to word formation. Stress is, in fact, crucial information for word formation. Leaving aside all the complexities, let us say that at the non-segmental PF system there is a module of word formation that makes a strict correlation between the stress underlying configuration, on the one hand, and word formation, on the other hand, such that the visibility of the main stress configuration defines the word at this level: one stress configuration visible to this module in a given location, one word; two stress configurations visible to this module in two different locations, two words. It seems clear that these locations are the positions of the functional heads $\mathrm{T}$ and Asp. Following the traditional approach, I will take morphology to be the module of word formation. Assuming that the visibility of the stress structure forces morphological interpretation, this configuration is read by the nonsegmental PF system the very moment it is visible. A temporal affix of futurity is derived in the case of the stress structure being visible only in the higher position of the functional chain (T, Asp) - T. ${ }^{12}$ An auxiliary is derived in the case of the stress structure being visible in both positions of this chain - T, Asp. Visibility in Asp generates the infinitive; visibility in $\mathrm{T}$ generates the auxiliary. It is clear that in this case $\mathrm{V}$ is not in $\mathrm{T}$ at PF.

Let us now turn to the morphic structure of Portuguese morphological futures. The constituents of the present future of 'amar' (love), are shown in (14):

12 This proposal may be compatible with the analyses in both Bisol (1994) and Mateus (1990) (see Fn.7), due to the conception of PF as a set of modules. 


$\begin{array}{ccc}\text { (14) am-a-r-e-i } & (1 \mathrm{sg}) & \text { 'I will love' } \\ \text { am-a-r-á-s } & (2 \mathrm{sg}) & \text { 'you-Sg will love' } \\ \text { am-a-r-á- } \varnothing & (3 \mathrm{sg}) & \text { 'he will love' } \\ \text { am-a-r-e-mos } & (1 \mathrm{pl}) & \text { 'we will love' } \\ \text { am-a-r-e-is } & (2 \mathrm{pl}) & \text { 'you-Pl will love' } \\ \text { am-a-r-ã-o } & (3 \mathrm{pl}) & \text { 'they will love' }\end{array}$

These constituents are: [Root + VTV + Aspect + Tense / Mood + Person / Number], respectively. The preterit future forms ahare the same morphic structure. We thus have here the exact mirror image of the syntactic functional heads that I have postulated - (Asp, T). The presence of these constituents in the morphic structure of the morphological futures gives additional support to the proposal that Asp and $\mathrm{T}$ are the functional heads of futurity in syntax. On the other hand, the fact that the morphological and periphrastic futures share the same chain of functional heads supports the claim that grammaticalization relates to the PF visibility of the functional heads. This being true, the difference between the morphological and periphrastic formations may simply be a matter of visibility to the PF system of the formal features of the functional heads, at a point of the derivation where these formal features are relevant to word formation: visibility at $\mathrm{T}$, and $\mathrm{T}$ only, for the morphological formation, and at both Asp and $\mathrm{T}$ for the periphrastic formation. In the case of the Portuguese future formations, the morphological form is more 'grammaticalized' than the periphrastic formation. The notion of grammaticalization apllies then, in this case, to the formation where only $\mathrm{T}$ was visible for word formation. Where does this intuition about grammaticalization come from?

I consider that there is a precise source for the intuition about grammaticalization: in the case of grammaticalization, the derivation starts from the information structure (thus, the $G$ plane), rather than from the lexical information (the L plane), in contrast with the less grammaticalized form, which has a derivation that starts from the relevant formal feature of the lexical head (the L plane). More clearly, I am suggesting that there are two possible ways of starting the derivation of the future interpretation from the heads (T, Asp, V). In Romance, these heads are as in (15): 
(15)

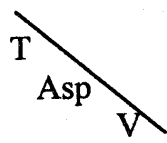

One possible way is to start from T. The other possible way is to start from V. If the derivation starts from $\mathrm{T}$, a single word is derived, because $\mathrm{T}$ c-commands the whole structure, so the whole structure (including $\mathrm{T}$ ) is immediately visible to the PF system. If the derivation starts from V, two words are derived, because Asp is visible to the PF system before $\mathrm{T}$, forcing the spelling-out of its c-commanded domain (Asp included). In this derivation, $\mathrm{T}$ is only visible to the PF system after Asp was made visible, and, when visible, forces the spelling-out of its c-commanded domain. However, this c-commanded domain does not contain Asp, V anymore, since Asp, V were already "stripped-away from the derivation" (to use Chomsky's terminology). If the derivation starts from $\mathrm{V}$, we have a derivation that starts from the $\mathrm{L}$ plane. If the derivation starts from $T$, we have a derivation that starts from the $G$ plane. There is intuition about there being grammaticalization precisely when the derivation starts from the $\mathrm{G}$ plane.

Summarizing, the morphological futures of stage (III) are the result of derivations that start from $\mathrm{T}$, while the periphrastic futures of stage (IV) result from derivations that start from V. Of course, I know that this is not yet full explanation of the facts. Full explanation requires explanation of the process of word formation, including the exact role of stress and involvement of formal features in this process. ${ }^{13} \mathrm{I}$ will leave this question open.

\footnotetext{
13 I also know that this is a new proposal, with far-reaching consequences for different theoretical issues, such as the representational or derivational status of the theory and the proper account of word order variation, crosslinguistically as well as concerning the different stages of the same language. For instance, it gives support to a representational theory of grammar, in the sense of a theory that accounts for the property of 'displacement' without the concept of movement in syntax. The theory I am suggesting is indeed, in some aspects, very similar to Brody's (1995) representational framework. For instance, both postulate the concept of chain rather than the concept of Move, and so eliminate syntactic derivations through movement. These two proposals are yet very different in other respects. For instance, they differ in the formal feature based character of the theory in this paper. This theory is also
} 
Another important issue related to the Romance futures concerns the causes of the change from a morphological to a periphrastic formation, and vice versa. Roberts \& Roussou (in preparation) and Roberts (2000), citing Fleischmann (1982), consider that the reanalysis of the auxiliary habere as a syntactic affix may be a direct reflex of the reanalysis of the full lexical verb habere as an auxiliary verb This is a reasonable hypothesis for this morphological formation, although it is not yet full explanation. We still need to know why stage (III) is a 'direct reflex' of stage (II). Moreover, what does it mean to be a 'direct reflex', in this context? In any case, this hypothesis implies that the reason of this change is internal to the properties of the futurity configuration. With respect to the periphrastic constructions (stages (II) and (IV) above), it iis reasonable to suppose that the development results from independent diachronic changes in the language, affecting the visibility to PF of the formal features of the functional heads T, Asp. This hypothesis is plausible, due to the loss of the active / deponent distinction during the Imperial period of Latin. Obviously, this loss altered the network of formal features for each verb of the language. It may be the case that, as a consequence of this change, the structure driving stress in the underlying structure expressing futurity was made visible at T and Asp, as opposed to visibility in only one position (T) in the previous stage. It is also possible that this independent change was the consequence of a more abstract change with cascate effects. What about the periphrastic construction of contemporary Portuguese? Which was, then, the change that took place and licensed it? Accepting the hypothesis that the periphrasis is motivated by changes that took place outside the domain of the futurity configuration, this change may be the shift that caused the distinction between Classical Portuguese and Modern Portuguese. A piece of evidence in favor of this hypothesis is the empirical observation that at the end of the 14th century the 'ir' + infinitive

\footnotetext{
similar but yet different from Bobaljik's (1995) copy theory. Bobaljik's framework postulates syntactic movement and explains the distinction between overt and covert movement as a phonological phenomenon relating to the spelling out of either the head or the tail of the syntactic chain produced by movement. The idea is that "in the event that there is more than one copy of a single element in a given syntactic representation, only one copy is pronounced in the general case" (Bobaljik 1995: 350). The similarity is the appeal to phonology to explain the effect of movement. One of the differences is that there is no syntactic movement chain in our framework. Since the syntactic chains are not produced by syntactic movement, there is no copy of elements either. A detailed explanation of the framework of this paper is presented in Lobato (in preparation).
} 
periphrasis was not yet purely temporal, as we have pointed out in Fn. 11. This hypothesis squares with the fact that the Modern period of the language began in 1500. If this analysis is correct, the cause of the emergence of the periphrastic constructions is outside the futurity configuration, in contrast with the emergence of the morphological construction. However, this is a highly tentative hypothesis, which has to be confronted with additional empirical information. Anyway, according to the proposal in this paper, the two types of change (towards morphological formation and towards periphrastic formation) relate to the use of formal features.

\section{Final comments}

This paper examined the derivation of the morphophonological shape of Portuguese past participles, including the change in stress placement that took place from Latin to Portuguese in these forms, and argued that the observed facts favor a theory of grammar in which linguistic construction and interpretation involve the same kind of element - formal features. The 'formal' property of these features derives from their absence of 'substantive' information, of the type found in features such as [Nasal], [Coronal]; [Human], [Animate]. It was assumed that grammatical semantic structure is the formal structure generated by the computational system. It consists of structural configurations of formal features. These configurations are semantic, but they drive phonological interpretation. Therefore, there is isomorphism between expression and content at this grammatical level. The formal features are then more abstract than the morphosyntactic features, such as gender and number.

The paper also argued that this kind of theory may straightforwardly account for diachronic change, and the case of the development of Romance future tense was examined. Parametric settings were said to relate to the location in which the configurations of formal features relevant to semantic interpretation are visible to the PF system. It was claimed that this proposal explains the change in stress placement that took place in past participles in the evolution from Latin to Portuguese. The development of future tense formations in Romance was claimed to be a consequence of a change in the visibility of the functional heads.. In the case of the Imperial Latin and Romance periphrastic formations, it 
was assumed that independent changes in the PF system may have altered the visibility of the functional heads. In the case of the Romance morphological formation, it was assumed with Roberts \& Roussou (in preparation) that it may be a reflex of the previous stage, which reanalyzed the full lexical verb habere as an auxiliary verb.

The proposal that there is a well-defined kind of feature shared by the different levels of construction and interpretation is indeed what one expects, if the design of the language faculty and the derivations in languages are in fact radically minimalist: the same type of feature is used to perform all types of operations in language (assembling of phonetic segments, generation of morphological and syntactic objects, and carrying out of phonological and semantic interpretations). How this occurs is a question for further investigation.

\section{REFERENCES}

Benveniste, E (1965) Structure des relations d'auxiliarité. Acta Linguistica Hafniensia. Copenhagen, vol IX (1): 1-15 (Reprinted in Problèmes de Linguistique Générale II. Paris, Gallimard, 1974). Bisol, L. (1994) O acento e o pé binário. Letras de Hoje, 29 (4): 25-36. BobalJik, J. (1995) Morphosyntax: The Syntax of Verbal Inflection. Cambridge, Mass. Ph.D. Dissertation, MIT.

BRody, M. (1995) Lexico-logical form: a radically minimalist theory. Cambridge, Mass., MIT Press.

Chomsky, N. (1995) The Minimalist Program. Cambridge, Mass., MIT Press.

(1998) Minimalist Inquiries: The Framework. MIT Occasional Papers in Linguistics, 15.

Hale, K \& S. J. Keyser (1993) On Argument Structure and the Lexical Expression of Syntactic Relations. In: Hale, K \& S. J. Keyser (eds.) The View from Building 20. Cambridge, Mass., MIT Press: 53-109. KROCH, A. (1994) Morphosyntactic variation. Beals, K. et al. (eds.) Papers from the 30th regional meeting of the Chicago Linguistics Society: Parasession on variation and linguistic theory. 
LightFoOt, D. (1991) How to Set Parameters: arguments from language change. Cambridge, Mass., MIT Press.

(1999) The Development of Language: Acquisition, Change, and Evolution. Oxford, Blackwell.

LoвAто, L. (1998) Uma proposta minimalista para o acento de palavra. (Paper read at the round-table A interface fonologia / sintaxe.) XIII Encontro Nacional da Anpoll. Campinas, Unicamp.

(1999) Sobre a forma do particípio do português e o estatuto dos traços formais. D.E.L.T.A., 15 (1): 113-140.

(in preparation) The Notion of Formal Feature and its Manifestations.

Mateus, M. H. M. (1990) Fonética, Fonologia e Morfologia do Português. Lisboa, Universidade Aberta.

Mattos e Silva, R. V. (1989) Estruturas Trecentistas. Elementos para uma Gramática do Português Arcaico. Lisboa, Imprensa Nacional - Casa da Moeda.

PIREs, A. (1996) As formas V-DO em português do Brasil: Características Sintáticas e Semânticas. M.A. Thesis. Brasília, Universidade de Brasília.

Roberts, I. (2000) The History of the Future. Paper presented at the Diachronic Generative Syntax VI

Roberts, I. \& A. Roussou (1999) A Formal Approach to “Grammaticalization”. Linguistics, 37 (6): 1011-1041. (in preparation) Features, Parameters, and Grammaticalization: A Minimalist Approach to Syntactic Change. To be published by CUP, Cambridge.

SaID Ali, M. (1919 / 1966) Dificuldades da Língua Portuguesa. Rio de Janeiro, Acadêmica. (The chapter on double participles was included from the 2 nd edition (1919) on. The last edition (6th edition) is from 1966.)

Wohlmuth, S. M. (1978) Lexicalization of the Irregular Past Participle in Hispano-Romance up to and including the Alfonsine Period. In: F. H. Nuessel, Jr. (ed.) Linguistic Approaches to the Romance Lexicon. Washinghton, D.C., Georgetown University Press. 